\title{
Regulation of Telecommunications: The Choice Between Market and Regulatory Failures
}

\author{
Dmitrii Trubnikov*
}

\begin{abstract}
Purpose - The paper examines the main regulatory frameworks of the telecommunications industry through the concept of market failure and analyses how and why the policy often leads to undesirable outcomes that might be considered as regulatory failure.

Methodology/approach/design - The research uses the EU regulatory framework for electronic communications as a base for the analysis of the main policy objectives through the prism of the market failure theory with an eye to the interests of the main market players in the telecommunications markets.

Findings - About any aspect of regulation allows to find ways to create opportunities for some groups of the industry and stifle activity of others. Despite the theory of market failure provides reasonable justifications for regulation of telecommunications markets, it is possible to argue that many of these problems are mainly the consequence of the policy and could be better solved by market mechanisms.

Originality/value - The results of the research allow to look at the problems of telecommunications development and issues of the high level of concentration of the telecommunications markets as regulatory formed problems rather than consequences of the inherited industry's characteristics.
\end{abstract}

Keywords: Liberalization, Market failure, Regulatory failure, Telecommunications, Competition.

*Candidate of Economic Sciences. Doctoral Candidate of Erasmus Mundus Joint International Doctoral (Ph.D.) Degree in Law, Science and Technology coordinated by CIRSFID, University of Bologna, Italy. Supervised by Tilburg Institute for Law, Technology, and Society (TILT), Tilburg University, the Netherlands, and Mykolas Romeris University, Vilnius, Lithuania. Email: d.trubnikov@uvt.nl.

The author is grateful to Ronald Leenes and Pierre Larouche for helpful comments and discussion. The views expressed in the article and any errors are those of the author. 


\section{Introduction}

Debates about the role of government in economy are very old. It has been incorporated in the mainstream of economics that market mechanisms sometimes lead to undesirable situations, so-called, "market failure", and, therefore, there are needs to interfere in the market in order to mitigate the problem. These interventions also can have a negative impact on the economy, and, such consequences can be considered as government or regulatory failure. ${ }^{1}$

The imperfection of the market seems as an apparent justification for the attempts to regulate the economic activity of human beings, but, at the same time, those groups of people who have a real access to the formation and exploitation of regulatory mechanisms have an enormous temptation and tremendous opportunities to use a legal system for their own benefits. Therefore, it is of a paramount significance to understand how regulation can be used for the interests of such interest groups and to expose the relationship between regulatory frameworks, that should be aimed to remedy market failure, with interests of those who create them or can have access to their formation.

Interesting examples where regulation provides wide opportunities for policymakers to enrich some powerful groups at the expense of society can be found in industries that heavily depend on innovations and play a significant role in modern society. The regulatory failures in these fields affect the public welfare, contribute to the growth of inequality and undermine incentives for innovations in the fields of the new economy. From this point of view, the telecommunications industry is an attractive area for such analysis, and, furthermore, the concentration of power in this industry allows to assume that this situation can be a result of the government activity in this area.

The article begins with a brief review of theoretical approaches to determination of market and government failures. The subsequent parts are devoted to the transformation of the landscape of telecommunications over the last decades and to the analysis of key issues of regulatory policy in the field. The main emphasis is made on the reasons for the government interventions in the telecommunications market from the positions of theories of market failure, and, at the same time, provides basic assumptions how and why these interventions lead to the policy failings and express in the oligopolistic structure of the industry.

\footnotetext{
${ }^{1}$ The term "regulatory failure" can be often met in academic literature with the same interpretation as government failure, but it can also mean the failing to achieve certain regulatory goals regardless of the economic aspects (see, e.g., Baldwin et al., 2012).
} 


\section{The theoretical approaches to determination of market and government failures}

In economics, the conception of "government failure" is another side of the coin of "market failure". Despite the idea of the supporters of the invisible hand that market mechanisms lead society to the increase of welfare for everyone, there is a widely accepted assumption that the market in a number of cases fails to achieve this goal and, thus, that there are needs for government intervention.

There are different views and understandings of what constitutes market failure, but the main reasons for government intervention are concentrated within the theoretical framework described by Joseph Stiglitz in the "Economics of the public sector" (Stiglitz, 1988): competition failure, necessity to produce public goods, presence of externalities, incomplete markets, imperfect information (or information asymmetry), unemployment and periodical instability, unequal distribution of incomes, "bad" consumers' decisions. According to his opinion the first six of these reasons directly relate to the problem of market failure and the latter two can be justified, even if market mechanisms work perfectly in economic terms, by the principles of justice, humanism and paternalism.

Meanwhile, it is also generally recognized that the problem of "market failure is only a necessary but not sufficient condition for governmental intervention" (Mazzucato \& Penna, 2016). Not only the market, but also regulatory bodies consist of self-interested agents and, as a result, decisions of policymakers, officials and bureaucrats can lead to the same or even worse outcomes than the activity of imperfect market mechanisms. Anyone who tries to participate in the creation of rules cannot be free from his personal interests, beliefs or biases. Acemoglu and Verdier (2000) point out that the necessity of government intervention often requires the choice between market failure and corruption, because the latter is the result of any intervention in the market since any intervention redistributes resources, and they conclude that corruption is merely "unavoidable price to dealing with market failure". "Corrupt incentives are the nearly inevitable consequences of all government attempts to control market forces" (Rose-Ackerman, 1978), and, that is why, some pundits even claim that they would prefer to live in the presence of market failure, rather than to have a risk of "widespread government failures" (Mills, 1986).

George Stigler (1971) in his "Theory of Economic Regulation" argued that the state "is a potential resource or threat to every industry in the society", and, therefore, the main players of the industry are tempted to capture this 
resource in order to maintain their positions. The appearance and development of public choice theory has allowed to look deeper at the problems of regulatory capture, and challenged the assumptions about the public interest nature of regulation (e.g. Buchanan \& Tullock, 1962; Holcombe, 2015). However, the regulatory capture is not the only factor that leads to the failure of regulation. There are numerous institutional aspects and there are also insufficient resources and epistemological limitations (Baldwin et al., 2012). We do not have knowledge about the future, we are not always able to assess the probability of certain events, and have to make our judgements under uncertainty relying on heuristics and biases (Tversky \& Kahneman, 1974), but, nevertheless, even such limitations can be used by those who have a political power in their own benefits.

Of course, it is not always clear, what more tilts regulation toward suppression of innovations and concentration of market power: regulatory capture or other regulatory failings, but understanding of the relationship between regulatory frameworks and interests of the main industry players is able to expose the roots of the problem.

\section{Transformation of the landscape of the telecommunications industry}

One of the main ideas of the "theory of economic regulation" (Stigler, 1971 ) is that regulation is used by private entities in order to hamper competition. It is even possible to find claims that the aim to suppress competition was among the main objectives in the regulatory policy of the US in the 1930s (Dempsey, 1989). These objectives were supported by the economic justifications for such decision making. For example, one of the rationales for legal suppression of competition in the industries that heavily depend on infrastructure, such as transportation or telecommunications, was based on the assumption that the immaterial nature of the products of such industries does not create incentives to invest in the expensive infrastructure without possibilities to obtain economic rent that could be provided by a monopoly position (Dempsey, 1989).

According to one of the explanations that justify the creation of entry barriers: " 'good regulation' is supposed to constrain entry so that the economies of single firm production can be achieved" (Joskow \& Rose, 1987). It is not a rare view in economics that monopolistic markets are able to provide more benefits to society rather than competition. Some even claim that "in an economic paradise, where a regulator is omniscient, benevolent, and able to fulfill any promise he makes, competition cannot improve upon regulated 
monopoly" (Armstrong \& Sappington, 2006). Such justifications perfectly supported monopolistic structure of telecommunications when this industry was entirely in the hands of the state. Indeed, before the end of the 1980s in most of the countries, regardless of capitalistic or socialistic character of their economy, telecommunications were under the full control of the governments as stateowned companies.

The most remarkable exception from the state-owned monopoly model was the telecommunications industry of the United States, where the major player was private company AT\&T. Strictly speaking, AT\&T was not the only company that provided telecommunications services in the US. There were also, so-called, independent telephone companies, but on most of the territory of the country AT\&T was able to establish a monopoly and became one of the biggest corporations in American history. AT\&T was a vertically integrated company that provided the full range of telecommunications services and produced telecommunications equipment for the industry. In 1974, the United States Department of Justice filed an antitrust lawsuit against the company, and the consequence of this action was the consent decree about divestiture of AT\&T in 1982. As a result, in 1984 the local operations of AT\&T were split into seven independent regional companies (Regional Bell Operating Companies also known as "Baby Bells"), while long distance business, as well as a production of telecommunications equipment, remained at that time under the control of AT\&T.

The process of creation of the competitive market in the EU started in 1987, when the Commission of the European Communities presented the Green Paper on the Development of Common Market for Telecommunications Services and Equipment. Despite the claim of this document about promoting "the development of new services by setting them in a more competitive framework" and necessity of "the transition toward a more competitive environment", the Green Paper also explicitly contained notification about "the major importance of scale effect" in this vital area of the modern economy. However, the scale effect is precisely one of those industrial characteristics that tilt industries toward high concentration, and, thus, the statement about its importance for the development of the industry quite contradicts with the claims about promotion of rivalry, if only we are not talking about the creation of oligopolistic market. Therefore, it seems plausible that the goal was the substitution of the state-owned monopolies across the Europe by the market where only several supranational giants will play the main role on the whole territory, rather than promoting the places under the sun for small and mediumsized businesses in this field. The current situation in the European market speaks in favor of this claim: the big companies from the advanced European economies have managed to take control over the industry in many less 
developed parts of the continent ${ }^{2}$, but it does not mean that small European countries were unable to develop the industry without such aid. The recent studies show that some Central and Eastern European countries not only demonstrated the higher level of competition and the presence of small and medium-sized enterprises in the industry during the first decade of the XXI century, but also have been able to leapfrog the most advanced economies of the EU in the development of fiber-optic infrastructure (Lemstra \& Melody, 2014; Serdarević et al, 2016; Rood, 2010).

Some scholars point out that the global process of liberalization was pushed by the US government in the interests of the US economy (Mueller, 2010), and some facts support this claim. The state-owned monopolies until the end of 1980s controlled not only telecommunications infrastructure and market of telecom services, but also the market of terminal equipment that could be connected to their networks, and the European decision about "liberalization" of telecommunications coincided with the changes in the structure of the global ICT equipment market. The first Directive of the reform in 1988 aimed to create a common market of end-user terminals (Commission Directive 88/301/EEC of 16 May 1988). In the middle of 1980s the former American telecom monopolist AT\&T launched an active campaign in the field of telecom equipment production in Europe: the company formed joint ventures with Philips Telecommunications B.V. in the Netherlands and with Telefonica in Spain (Noam, 1992), and acquired 25\% share of Italian Olivetti S.p.A.. In 1989, Italian state-owned telecom manufacturer Italtel chose AT\&T as a partner for its plans to upgrade Italian network with estimated budget of $\$ 30$ billion (Hochheiser, 1990). The agreement between AT\&T and Italtel also called for joint development of new products, and, according to some opinions, provided AT\&T the basis to be a major player in the future European telecom market (Hochheiser, 1990).

This shift of the regulatory policy of telecommunications allows to suppose that whether the whole preceding period of regulation in this field was based on fragile theories or the current approach is not the best from the point of view of the public interest. Moreover, we can also suggest that regardless of a dominant theory at any particular period these theoretical propositions can be used by those who have power to implement them in the public policy or,

\footnotetext{
${ }^{2}$ Some scholars notice that " $[t]$ he internationalization of EU incumbents could not have taken place without liberalization of entry regulation and would have been difficult without progress on unbundling and privatization" and that "the most international of the EU's Multinational telecoms ... incumbents emerged from the larger continental economies: France, Germany, Spain and Italy" (Clifton, Díaz-Fuentes \& Revuelta, 2010).
} 
furthermore, even such dominance of a point of view in economics can be a result of interests of policymakers.

Of course, it could be argued that this change was warranted by the technological breakthrough in the ICT industry, but such explanation does not provide a comprehensive answer to the question about the main beneficiaries of the policy, especially, if we look how the problem of the shortage of supply of ordinary phone services has been solved after the implementation of market mechanisms in different parts of the world ${ }^{3}$. Moreover, even economic theories supported the claim about subadditivity of fixed phone services, that provided a scientific basis for the natural monopoly structure of the area, were constantly challenged by the empirical evidences (Spulber \& Yoo, 2013). At the same time, the processes of "deregulation" and "privatization" in telecommunications also do not prove the presence of the "public interest based" approach in the regulatory policy. A captured regulation can easily take a form of "liberalization" and maintain the interests of powerful groups of society. Despite the fact that European reform of the industry could be considered as a proper way toward the creation of a competitive market in this field, it cannot exclude the supposition that in reality the interests of a big business did play an important role in the implemented policy.

\section{Key issues of the telecommunications policy}

It is generally assumed that the process of demonopolization of telecommunications in Europe can be considered as a period of "deregulation" and "liberalization" of the industry (Koenig et al., 2002), but this terminology can be quite misleading. Indeed, the state has not retreated from the telecommunications industry and has continued to play a significant role in the field, however, it "has taken on a host of new functions ... in the new institutional arrangements" (Grande, 1994). No doubt that during this period there were some efforts toward the creation of rivalry in the market, even if in an oligopolistic form, and there was a real transformation of property rights from the states to private entities, but there was also creation of new institutional environment that imposed new regulatory burdens on the new participants of the telecom business.

\footnotetext{
${ }^{3}$ E.g., Armstrong \& Sappington (2006) analyze the development of the industry in Chile and shows that that "liberalization" allowed to increase the number of fixed lines more than three times between 1992 and 2000. The similar picture can be found, for example, in Russian telecommunications.
} 
According to the EU regulatory framework for electronic communications there are three main objectives of regulation in this field: strengthening of competition, stimulation of investment, fostering of consumers' freedom of choice and "enable them to benefit from innovative services, quality and lower rates"4. From the European Directives aimed to achieve these goals we can distinguish several key aspects, that try to solve the problems that, allegedly, cannot be solved by market mechanisms: (1) the strategic planning and distribution of limited resources such as radio spectrum, (2) access to network elements and associated facilities, (3) the necessity of integrity and security of networks and services, (4) the harmonization of networks, associated facilities and services through standardization, (5) control over companies that have significant market power and (6) the social significance of telecommunications services.

These aspects are universal issues in telecommunications industry not only in the EU, but also in other parts of the world, where current economic conditions are sufficient for the development of this area. The analysis below provides the view on these aspects through the prisms of the theories of market and government failures.

\subsection{The strategic planning and distribution of limited resources such as radio spectrum}

The theory of market failure justifies the government activity in this area through the problem of externalities, because according to the basic assumption unregulated use of radio frequencies will make impossible the efficient utilization of the spectrum due to the problem of interference. The "doctrine of spectrum scarcity" prevailed in the regulatory policy of telecommunications during the XX century and still plays the main role in the issues devoted to the planning and distribution of radio frequencies. In 1959, Ronald Coase introduced the idea of tradability of radio spectrum (Coase 1959), and since the last decades of the XX century various countries have gradually adopted these principles in their regulatory frameworks.

While the Coasean approach of the distribution of radio spectrum expands to new geographic territories like European Union ${ }^{5}$, it is very important to notice that nowadays the development of radio technologies allows to make

\footnotetext{
${ }^{4}$ Summaries of EU legislation: Regulatory framework for electronic communications (http://eur-lex.europa.eu/legal-content/EN/TXT/?uri=uriserv:124216a).

5 See Decision No 243/2012/EU of the European Parliament and of the Council of 14 March 2012.
} 
claims that the scarcity of radio spectrum is a common misconception (e.g. Staple \& Werbach, 2004), or that "new technologies promise to replace scarcity with abundance, dumb terminals with smart radios able to adapt to their surroundings, and government-defined licenses with flexible sharing of the airwaves" (Werbach, 2004). From such point of view the efficiency of radio spectrum utilization can be achieved through the reuse of the frequencies, implementation of "smart" antennas, advanced methods of modulation and other technological improvements. The radio spectrum by its nature is a common resource and, thus, the creation of the exclusive rights on the usage of this common good reduces diversity of available technologies, contributes to the market concentration (Trubnikov, 2017) and reasonably induces concerns from society. Lawrence Lessig (2007) compares the distribution of radio spectrum through auctions with the distribution of the "right to sell hotdog", and that introduces the problem in a very straightforward manner.

In general, the solution of the problem of distribution of radio spectrum is placed between two extremes. One of them is the propertization of radio frequencies, and, despite the common relationship between the market and property, it hardly can be considered as "liberalization", because it just transforms the common property into the hands of private entities. In this case the link between the high market concentration and the market imperfection is just an illusion caused by the fact that market mechanisms play some role after the privatization of the common resource, but since the establishment of such rules is the result of government intervention into the realm of commons and the artificial limitation of the resource that hypothetically is not so scarce, it could be argued that the competition failure is rather the government failure than the market inability to resolve the issue. Moreover, since market mechanisms play such secondary role in the process of frequencies allocation we cannot claim that this concentration is the result of the victory in the market competition merely because such competition has not been possible. This market was doomed by the state to be an oligopoly even before it was created. ${ }^{6}$ However, this approach can be considered, to some extent, as "deregulation", because after the assignment of property rights, the allocation of resources toward the highest valued use could be under the market mechanisms.

The alternative is a real liberalization of radio spectrum, and the role of government in such a case is to manage availability of this resource to everyone and prevent interference and fraud. This approach is, possibly, more difficult in implementation. It requires thorough and comprehensive analysis of the existing

${ }^{6}$ Melody (2012), e.g., notes that in the EU " $[\mathrm{t}]$ he liberalisation objective of stimulating competition and opening access apparently was not considered to be the cornerstone of spectrum policy". 
technologies, monitoring of their development, creation of regulatory policy and enforcement of these rules. It is even possible that future technologies will allow us to completely open the spectrum and manage its distribution without any direct intervention of government, but, then, this future openness should be a purpose of the current regulatory efforts. The role of government in such conditions would be still very important, because the regulation must provide the solution for other related issues such as, for example, ecological problems caused by the usage of radio technologies in order to protect citizens from the abuse of electromagnetic waves by the market players, or, as Lessig suggests, the government could "simply be assuring that the technologies that use the spectrum are properly certified technologies" (Lessig, 2001).

\subsection{Access to network elements and associated facilities}

This aspect includes two parts, and both of them can be explained by the competition failure of the market. European regulation, for example, imposes an obligation to share facilities and network elements of the operators that have significant market power (Directive 2002/19/EC of the European Parliament and of the Council of 7 March 2002). The first part is devoted to the necessity of interconnection of different networks, and in this case, incumbents can easily prevent potential competitors from the entry to the market. Therefore, the importance of the regulation of this issue has significant value for the promotion of rivalry in the industry. Meanwhile, the second part is not so obvious and can be challenged by some suppositions.

It is necessary to bear in mind that the initial efforts to solve the problem of telecom monopolies by no means had relation to the realm of market failure. These monopolies in European countries were state-owned companies and they had to be privatized according to the new regulatory frameworks. The significant market power of new powerful players was the direct consequence of the positions of their predecessors. Moreover, it was the direct consequence of the way of their privatization. The agenda of the European reform of the industry did not envisage the horizontal separation of these monopolies before privatization. Moreover, there was a claim that the single European market will allow to benefit from economies of scale, that, according to some opinions, was not possible within the borders of one country (Koenig et al., 2002). However, the noticed in Section 3 examples of Central and Eastern European countries clearly testify against the necessity of such supranational scope of economies of scale for the telecom development. Furthermore, new entrants of the new 
"demonopolized" market of Europe were not able to benefit from economies of scale and scope ${ }^{7}$ due to the regulatory constraints, since the process of "demonopolization" occurred bit by bit, service by service. ${ }^{8}$ It took about 10 years before all services were placed in the competitive environment. Moreover, not only services but even telecommunications infrastructure was not placed in the competitive market in the beginning of such kind of "liberalization", and, consequently, potential entrants were not allowed to develop their business independently and had to rely on the accessibility of the incumbents' infrastructure and on their capability to get this access. Such slowness of the "liberalization" could be easier explained by the willingness to control the innovation development of the industry by the interest groups rather than by any public needs.

Competition policies, that intend to promote rivalry in highly concentrated industries, pay attention to peculiar industry features and try to facilitate competition through the alleviation of the influence of them on entry. The significant part of the regulatory efforts is dedicated to the problem of monopolistic bottlenecks, such as local loops, that can be considered as essential facilities of network infrastructure (De Bij1, 2005). However, it might be argued that facilities-based competition is able to reduce the needs for the regulation of the bottlenecks (Canoy, De Bijl \& Kemp, 2003) and provides more efficient outcome of the development of network infrastructure compared to servicebased competition (Yoo, 2014), while the latter has been the main target of the European "pro-competition" policy in the industry. Moreover, the problem of the bottlenecks can be per se a consequence of regulation and can be solved by the implementation of new technologies or new approaches in the development of the networks (Trubnikov, 2017). In other words, the existence of "monopolistic bottlenecks" is the result of the previous industrial policy, and the efforts that aim at the alleviation of the problem rather than to the alteration of the industry structure provide advantages to the most powerful actors of the market, and, thus, might be considered as an example of government failure.

\footnotetext{
${ }^{7}$ Results of some researches show that economies of scale played a less significant role in telecommunications than economies of scope (Bloch et al., 2001)

${ }^{8}$ In 1988 was opened the terminal equipment market, in 1990 market for "non-voice services and voice services for closed groups", in 1994 satellite services, in 1995 Cable $\mathrm{TV}$, in 1996 mobile communications and from 1 January 1998 voice telephony services.
} 


\subsection{The necessity of integrity and security of networks and services}

This problem can be represented through different approaches in terms of market failure. Firstly, supporters of paternalism can argue that people could choose services of low quality because they are cheaper, and, thus, there are needs for government intervention. Secondly, in case of lack of competition nothing forces incumbent to maintain sufficient quality of their services, and, therefore, government must solve the competition failure problem. Thirdly, there is a problem of information asymmetry. It could be quite plausible that a company can sacrifice security or quality issues for profits, hiding the actual information about services from its customers, or even worse, a company can deliberately neglect important issues for some reasons and provide wrong information to customers.

The paternalistic outlook is a matter of taste and values of a researcher and discussion about it can be infinite and futile, but two other justifications for the interventions in the market can be the objects of analysis. If the competitive environment has not been achieved, then arguments for government control of the network integrity and security are quite robust, but it does not explain the regulation of small players, which try to survive in the presence of powerful rivals. Meanwhile, since the information asymmetry plays a significant role in the telecommunications business, the activity of even small companies indeed could unfairly harm the interests of customers, but this is a problem of provision of fair information, rather than a problem of integrity and security. Otherwise, it is again the issue from the realm of paternalism. However, the asymmetric regulation of telecommunications companies depending on the size of market share seems like a reasonable answer to the imperfection of market mechanisms in this aspect. Small market participants in order to benefit from the network effect of the entire network are forced to adjust their activity to the standards and technologies that have been established on the market, while incumbents have temptation to prevent weak rivals from these benefits. Katz and Shapiro (1985) pointed out this phenomenon in their seminal work dedicated to the analysis of network externalities.

Meanwhile, the drawbacks of the government activity in this field are expressed in economic and social issues. Such regulatory efforts increase the costs of the roll-out of networks and, thus, decrease the territory that could be commercially interesting for the business, and, as a result, contribute to the problem of "digital divide". At the same time, compliance with the rules can have pronounced impact on economies of scale, and, thereby, provides cost advantages for the big players of the market, contributing to the concentration of the market in the hands of big business. Based on the foregoing, we have to 
admit that this area is quite subtle for the regulatory activity. Solution of such imperfectness of market mechanisms can easily take the form of over-inclusivity and, thus, over-regulation, and lead to the creation of monopolistic or oligopolistic markets.

\subsection{The harmonization of networks, associated facilities and services through standardization}

It is widely believed that the market also cannot achieve efficiency due to inability to coordinate market actors. Using the terms of the described earlier approach to the issue of market failure, this problem derives from the information asymmetry or incomplete information. It is easy to imagine, that without standardization some market actors, due to the lack of information, can choose technology, that is not interoperable with the technology that is used by other market actors, and, as a result, they will not be able to connect their networks or to provide the full range of services. However, the problem of incomplete information does not give a full clarification of the issue. The lack of standards provides opportunities to lock-in customers on the particular technology, and these costumers are not only end-users of telecommunications services, but also providers of these services. The entire business of these companies and also their ability to adopt new innovative technologies can be locked-in on a particular producer of a proprietary standard. The relationship between these costumers and the owners of proprietary technology can be also considered through the monopolistic problem, because the supplier in this situation becomes a single supplier on the market of a particular technology.

Despite the rationales for government intervention described above, the regulation of this field also provides opportunities for government to fail in achieving a socially desirable outcome. First of all, it could be a problem of QWERTY-effect that locks the industry in a particular technology despite the presence of better solutions. A more serious problem is if an adopted technology is not suitable for the future development, even if at the moment of adaptation it showed sufficient or even better results than alternatives. The fact that among the most prevalent standards of Internet access in the western Europe are DOCSIS and xDSL, but not FTTx (OECD, 2015), is, possibly, a problem of this kind. Yoo (2014), for example, notices that due to the standardization policy of the French regulator, former monopolist Orange even in 2010 aimed to increase the ADSL coverage to $99 \%$ by 2013 , while in many eastern European countries by that time the significant part of the subscribers had broadband access through fiber-optic infrastructure (Rood, 2010; FTTH Council Europe, 2012). The worst situation is adaptation of a standard due to the adjustment of regulation to the 
interests of powerful groups at the expense of public interests. The consequences of this adaptation is not only lock-in on the inferior technology, but also the contribution to the concentration of resources in the industry.

\subsection{Control over companies that have significant market power}

It was one of the first justification of the government presence in the economic activity. If industry's inherited characteristics tilt this industry toward monopoly, then Pareto efficiency will not be achieved and, thus, government should find ways to move the prices closer to the competitive level. It is necessary to notice that in the light of legal systems of developed countries monopolies are not illegal per se, but some conduct of companies with significant market power may result in antitrust liability. The skeptical view on government intervention induced by the market concentration was intensely promoted by the Chicago School and has found its significant place in the contemporary antitrust policy (Posner, 1979).

The common arguments of liberal economists are based on the assumption that monopoly is formed by market, and, thus, in many cases this situation could be considered as a better allocation of resources from the point of view of "consumers welfare", but the broader view on the problem of "government failure" allows to look at the picture from another viewpoint. Significant market power of telecommunications companies can be the direct consequence of the set of previous decisions of policymakers, and it even does not matter whether the reason of these interventions was market failure, rentseeking, cronyism or corruption. Therefore, if the positions of major players are the result of regulation, then it must be difficult to justify a passive role of the regulator in such cases of competition failure even from the liberal viewpoints.

Monopolies of the ICT industry in general, and monopolies of telecommunications in particular, can be dangerous, not only in the sense of threats to "consumers' welfare", but also from social and political perspectives. Since the information and communication industry is the driving force of the modern economy, it is possible to infer that the concentration of power in the industry leads to the concentration of wealth in the hands of the most powerful players of this field. Meanwhile, it is a widespread view in the areas of economics and social sciences that concentration of wealth can threaten our freedom and democratic principles of modern society (Acemoglu et al., 2013; Murphy, 2015). The increasing inequality can lead to the growth of "extractive institutions" that served the interests of ruling classes (Acemoglu \& Robinson, 2012) and, eventually, can "have a negative effect on the rule of law ... and ambiguous effects on regulation" (Murphy, 2015). This situation, possibly, 
requires revision of the purposes of competition law and elaboration of new methods and approaches in this area.

\subsection{The social significance of telecommunications services}

The unchallenged importance of ICT for the modern world gives birth to ideas that significantly affect the regulatory policy of this field. Even in the realm of human rights nowadays we can find the idea that human beings have a right to Internet access and that they should not be discriminated in this right. ${ }^{9}$ The policymakers of many countries eagerly try to incorporate this idea into the efforts of subsidization of the development of telecom infrastructure. However, even the presence of the problem of digital divide in the second decade of the XXI century in the developed parts of the world is able to raise reasonable questions about the real sources of this issue.

Meanwhile, "direct subsidy of money" according to Stigler (1971) is "the most obvious contribution that a group may seek of the government". The shortage of competition increases deadweight loss and expresses in the shortage of supply in the market. As we analyzed above, the shortage of competition can be not only a result of the government failings in the solution of the task of promotion of rivalry, but also the consequence of regulatory policy in other fields, such as radio spectrum distribution or even necessity to maintain harmonization, integrity and security of networks. The ideas that freeing of some parts of radio spectrum would allow to solve the problem of provision of telecommunications services in rural areas can be met in academic literature in the beginning of the 2000s (Compaine, 2003; Wanichkorn \& Sirbu, 2002), but instead, "emphasis on bringing broadband to low density areas continues to look at the cost of "wiring" (Compaine, 2003).

Another idea that prevails in the regulatory efforts in this aspect is the equalization of inhabitants of urban and rural areas. ${ }^{10}$ Numerous "digital agenda" of various countries includes not only the necessity of provisioning the access to modern information services, but also impose minimal requirements to these services (OECD, 2015), that can be understood as a mechanism of "control over entry". Indeed, if the problem of Internet access in some particular village

9 One of Wikipedia articles is even dedicated to this issue https://en.wikipedia.org/wiki/Right to_Internet_access.

${ }^{10}$ The interesting fact is that even the idea of the "universal service" per se "was a stunning strategic action" of the president of AT\&T Theodore Vail that allowed the company to gain the monopoly in the United States by means of the government protection of the business of AT\&T from competition (Grove, 2003). 
can be solved with implementation of a particular radio technology, the requirements of provision of speeds equal or over, for example, 30 or $100 \mathrm{Mbit} / \mathrm{s}$ (OECD 2015) can deter alternative players to enter the market. Moreover, it is even not clear that broadband access with different characteristics can be considered as a part of the problem of digital divide. It can also be argued that nowadays basic telecommunications services are comparatively cheap and they could be even cheaper if the market would be more competitive, while direct public investments in the development of the industry create advantages for those who get it, and, thus, negatively affect rivalry.

Digital divide is not the only idea that has been embraced by the regulation of ICT industry in general and telecommunications particularly. There are also important issues of freedom, privacy, security, child protection and so on, and there are no doubts that all of these problems are of paramount significance for the modern society, but the question here is the appropriate balance between market mechanisms and regulation. The results of regulatory failings in these subtle aspects could be even more destructive than merely creation of advantageous conditions for some companies in the industries of the $\mathrm{XX}$ century. It is also possible to admit that at least some of these problems are mainly the consequence of regulation, and could be better solved by the market, while regulatory activity in this field contributes to the processes of monopolization, and, eventually, will aggravate other issues such as freedom, privacy and inequality.

\section{Conclusion}

The given analysis of the main regulatory frameworks through the positions of the concept of market failure with an eye to the interests of the main market players in telecommunications industry allows to draw the following conclusions:

First of all, the current way of development of the telecommunications industry is the result of previous policy decisions in this field, and the dominance of supranational companies in the world market can be considered as the consequence of regulatory efforts rather than inherited industry's characteristics. The prevalence of the idea of the importance of "economies of scale" in telecommunications for the development of the new economy has contributed to the processes of privatization that occurred during the last decades and has allowed transnational giants to take control over the former national monopolies, forming the global oligopolistic market. 
Secondly, even "privatization" and "liberalization" processes in telecommunications do not allow to conclude that the "public interests based" approach dominates in the regulatory policy. About any aspect of regulation allows to find ways to provide opportunities for some groups of the industry and stifle activity of others. Self-interested policymakers have favorable opportunities to explain their decisions through the needs of maintenance of the digital economy, solution of social problems, interests of national defense or harmonization of networks.

Thirdly, telecommunications industry is not necessarily the business of big corporations that try to convince the policymakers that rivalry in this area can endanger "the long-term health of the ... digital economy" (Vodafone, 2015). This industry is able to give opportunities for small enterprises to be active in the market and to enable consumers to benefit from innovative activity of these companies, for whom only flexibility and innovations provide possibilities to survive in the competitive environment.

Fourthly, despite the seeming necessity to maintain the integrity, security and harmonization of networks, as well as to provide solution for other important aspects, the reasons to extend regulation in the activity of alternative companies are very doubtful. The alternative companies are forced to maintain integrity and harmonization due to the presence of market forces. In order to benefit from the network effect of the entire network, rather than limit this benefit by the scope of their private networks, they are forced to harmonize their networks with facilities of other market participants, and this is one of those cases where market mechanisms are able to work better than government intervention. However, it does not exclude the necessity to regulate the activity of incumbents and weaken their positions in the market in order to remedy the competition failure, that, as we have seen above, could be not only the result of the market imperfection, but also the consequence of regulatory activity.

Finally, the problem of "digital divide" can be considered as an example of deadweight loss caused by government intervention in the market. The high cost of compliance moves the supply curve and, thus, decreases the quantity of the goods in the market. However, it does not mean that the total absence of regulation could provide better results. Inability of government to effectively solve the problem of externalities, like in case with radio frequencies distribution, hampers the entrance of small business in this field and, thus, contribute to the undersupply in the market. 


\section{References}

Acemoglu, D., \& J. Robinson (2012). Why Nations Fail: The Origins of Power, Prosperity, and Poverty. New York: Crown Business.

Acemoglu, D., S. Naidu, P. Restrepo, \& J. Robinson (2013). "Democracy, Redistribution and Inequality”, NBER Working Paper No. 19746.

Acemoglu, D., \& T. Verdier (2000). "The choice between market failures and corruption", American Economic Review, 90(1): 194-211.

Armstrong, M., \& D. Sappington (2006). "Regulation, Competition and Liberalization”, Journal of Economic Literature, 44(2): 325-366.

Baldwin, R., M. Cave, \& M. Lodge (2012). Understanding Regulation: Theory, Strategy, and Practice. Oxford University Press, 2012.

Bloch, H., G. Madden, \& S. Savage (2001). "Economies of Scale and Scope in Australian Telecommunications", Review of Industrial Organization, 18(2): 219-227.

Buchanan, J. M., \& G. Tullock (1962). The Calculus of Consent: Logical Foundations of Constitutional Democracy. Ann Arbor: University of Michigan Press.

Clifton, J., D. Díaz-Fuentes, \& J. Revuelta (2010). "The political economy of telecoms and electricity internationalization in the single market", Journal of European Public Policy, 17(7): 988-1006.

Canoy, M., de Bijl, P., \& R. Kemp (2003). "Access to Telecommunications Networks", TILEC Discussion Papers, No. DP 2003-07.

Coase, R. (1959). "The Federal Communications Commission”, Journal of Law and Economics, 2: 1-40.

Compaine, B. (2003). "Revisiting Cost and Affordability Assumptions for High Speed Data Services in Low Population Density Locations", Telecommunications Policy Research Conference.

De Bijl, P. (2005). "Structural Separation and Access in Telecommunications Markets", CESifo Working Papers, No. 1554.

Dempsey, P. S. (1989). "Market Failure and Regulatory Failure as Catalysts for Political Change: the Choice Between Imperfect Regulation and Imperfect Competition", Wash. \& Lee L. Rev., 46(1): 1-40. 
FTTH Council Europe (2012). Creating a brighter future. Fiber to the home: Taking your life to new horizons! Press conference - BBWF Amsterdam, 16 October 2012. Available at http://www.ftthcouncil.eu/documents/Presentations/20121016PressConfB BWF.pdf

Grande, E. (1994). "The New Role of the State in Telecommunications: an International Comparison", West European Politics, 17(3):138-157.

Grove, A. (2003). "Churning Things Up Innovations with the power to transform entire industries are the Holy Grail of business strategy. Unfortunately, the innovators don't always survive." FORTUNE Magazine, August 11, Available at http://archive.fortune.com/magazines/fortune/fortune_archive/2003/08/11 /346796/index.htm

Hochheiser, S. (1990). "The American Telephone and Telegraph Company (AT\&T)" in Fritz Froehlich (ed.), The Encyclopedia of Telecommunications, vol.1. New York: Marcel Dekker Inc.

Holcombe, R. G. (2015). Political capitalism. Cato Journal, 35(1): 41-66.

Joskow, P. L., \& N. L. Rose (1987). "The Effects of Economic Regulation", Working Paper, Department of Economics, MIT, No 447.

Katz, M. L., \& C. Shapiro (1985). "Network Externalities, Competition, and Compatibility", American Economic Review, 75(3): 424-440.

Koenig, C., Bartosch, A., \& J.-D. Braun (2002). EC Competition and Telecommunications Law: A Practitioner's Guide. Kluwer Law International.

Lemstra, W., \& Melody, W. H., Eds. (2014). The Dynamics of Broadband Markets in Europe - Realizing the 2020 Digital Agenda. Cambridge, UK: Cambridge University Press.

Lessig, L. (2001). The Future of Ideas: The Fate of the Commons in a Connected World. New York: Random House.

Lessig, L. (2007). "Internet Policy: Deregulating Spectrum." http://www.lessig.org/2007/02/internet-policy-deregulating-s/.

Mazzucato, M., \& Penna, C. C. (2016). "Beyond market failures: The market creating and shaping roles of state investment banks", Journal of Economic Policy Reform, 19(4): 305-326. 
Melody, W. H. (2012). "Viewpoint: The Closing of the Liberalization Era in European Telecommunication”. Competition \& Reg. Network Indus, 13, 218-235.

Mills, E. S. (1986). Burden of Government. Hoover Press.

Mueller, M. L. (2010). Networks and states: The global politics of Internet governance. MIT press.

Murphy, R. H. (2015). "The Impact of Economic Inequality on Economic Freedom", Cato Journal, 35(1): 117-131.

Noam, E. M. (1992). Telecommunications in Europe. New York: Oxford University Press.

OECD (2015). OECD Digital Economy Outlook 2015.

Rood, H. (2010). "Very High Speed Broadband Deployment in Europe: The Netherlands and Bulgaria Compared", Telecom Policy Research Conference, Arlington, VA: TPRC.

Posner, R. (1979). "The Chicago School of Antitrust Analysis", University of Pennsylvania Law Review, 127(4): 925-948.

Rose-Ackerman, S. (1978). Corruption: a Study in Political Economy. New York: Academic Press.

Serdarevic, G., Hunt, M., Ovington, T., \& Kenny, C. (2016). "Evidence for a Ladder of Investment in Central and Eastern European Countries", Telecommunications Policy, 40: 515-531.

Spulber, D. F., \& Yoo, C. S. (2014). “Antitrust, the Internet, and the Economics of Networks". In R. D. Blair and D. D. Sokol eds. Oxford Handbook of International Antitrust Economics, Oxford University Press; Available at SSRN: https://ssrn.com/abstract $=2370050$

Staple, G., \& K. Werbach (2004). "The End of Spectrum Scarcity", IEEE Spectrum, 41(3): 48-52.

Stigler, G. J. (1971). “The Theory of Economic Regulation”, The Bell Journal of Economics and Management Science, 2(1): 3-21.

Stiglitz, J. E. (1988). Economics of the Public Sector. WW Norton \& Company.

Trubnikov, D. (2017). “Analysing the Impact of Regulation on Disruptive Innovations: The Case of Wireless Technology". Journal of Industry, Competition and Trade, 1-22. doi:10.1007/s10842-016-0243-y 
Tversky, A., \& D. Kahneman (1974). "Judgment Under Uncertainty: Heuristics and Biases", Science, 185(4157): 1124-1131.

Vodafone Group (2015). Vodafone and Europe: Investing for the Future. Vodafone Group Plc.

Wanichkorn, K., \& Sirbu, M. (2002). "The Role of Fixed Wireless Access Networks in the Deployment of Broadband Services and Competition in Local Telecommunications Markets". Telecommunications Policy Research Conference.

Werbach, K. (2004). Radio Revolution: The Coming Age of Unlicensed Wireless. New America Foundation.

Yoo, C. S. (2014). "US vs. European Broadband Deployment: What Do the Data Say?" U of Penn, Inst for Law \& Econ Research Paper. No. 14-35. Available at SSRN: http://ssrn.com/abstract=2510854. 
TRUBNIKOV, D. Regulation of Telecommunications: The Choice Between Market and Regulatory Failures. The Law, State and Telecommunications Review, v. 9, n. 1, p. 25-46, May 2017.

[DOI: https://doi.org/10.26512/lstr.v9i1.21511] 